\title{
Comparative study of oral mifepristone and endocervical prostaglandin-E2 gel as pre-induction cervical ripening agents in parturition
}

\author{
Prabhkiran Dhillon, Manash Biswas, Priyanka Tripathi, Vinod G. Nair*
}

Department of Obstetrics and Gynecology, Base Hospital Delhi Cantonment, Delhi, India

Received: 16 July 2020

Revised: 15 August 2020

Accepted: 18 August 2020

\author{
*Correspondence: \\ Dr. Vinod G. Nair, \\ E-mail: nair.vinod19@gmail.com
}

Copyright: (C) the author(s), publisher and licensee Medip Academy. This is an open-access article distributed under the terms of the Creative Commons Attribution Non-Commercial License, which permits unrestricted non-commercial use, distribution, and reproduction in any medium, provided the original work is properly cited.

\section{ABSTRACT}

Background: Intracervical instillation of prostaglandin E2 is a well-known and widely practiced method of preinduction cervical ripening. Mifepristone, due to its anti-progesterone action has been found to be a potential cervical ripening agent. This study was conducted to compare the safety, efficacy and outcome of these two drugs in preinduction cervical ripening.

Methods: One hundred antenatal women were recruited for the study; 50 in mifepristone arm and 50 in PG-E2 gel arm. Any singleton term pregnancy in vertex presentation with intact membranes and bishop's score of $<4$ was included in the study. Any contraindication for vaginal delivery and any contraindication for mifepristone or PG-E2 were considered as exclusion criteria. Participants in the mifepristone arm were given tablet mifepristone $200 \mathrm{mg}$ orally and those in PG-E2 gel group received endocervical instillation of PGE2 gel $0.5 \mathrm{mg}$, two doses 6 hours apart (if necessary). Induction of labour was considered successful if the parturient delivered within 48 hours of administration of mifepristone or first dose of PG-E2 gel, with or without labour augmentation with oxytocin. Delivery after 48 hours and caesarean delivery were considered unsuccessful induction.

Results: There was a significant improvement in bishop's score in mifepristone group 5.0 \pm 1.55 as compared to PGE2 gel group 3.64 \pm 2.14 ; $p$ value 0.001 .

Conclusions: Oral administration of $200 \mathrm{mg}$ mifepristone is a safe, effective and convenient alternative to intracervical instillation of prostaglandin-E2 gel for pre-induction cervical ripening.

Keywords: Bishop's score, Cervical ripening, Induction of labour, Mifepristone

\section{INTRODUCTION}

Induction of labour is one of the most commonly performed interventions in modern obstetrics with up to $25 \%$ of pregnant women having labour induced in many developed countries. ${ }^{1}$ Induction can be defined as an intervention intended to artificially initiate uterine contractions resulting in the progressive effacement and dilatation of the cervix which will result in the birth of the baby by vaginal route. Various mechanical and pharmacological methods are employed for inducing labour. The success of any method of induction depends largely on parity of the parturient and favourability of cervix at the beginning of induction. In most centers, bishop score (1964) is used to assess the favourability of the cervix prior to induction. ${ }^{2}$ A bishop's score of 6 or less often indicates that induction is unlikely to be successful. In these unfavourable cases for induction, preinduction cervical ripening with prostaglandin E2 gel or mifepristone has a role to play for making the cervix more favourable.

Intracervical instillation of prostaglandin E2 is a wellknown and widely practiced method of pre-induction 
cervical ripening. Mifepristone/RU-(486), a new class of pharmacological agents (antiprogestins) has been developed to antagonize the action of progesterone. Mifepristone is used for cervical ripening in late pregnancy by antagonizing progesterone, thus increasing uterine contractility and by increasing the sensitivity of the uterus to the actions of prostaglandins. ${ }^{3}$ Mifepristone is administered orally and is readily absorbed. Serum mifepristone levels reach a maximum in one hour after oral administration of single dose ranging from 50 to $800 \mathrm{mg}$ and thereafter, the serum levels plateaus for 24 hours or more. Mifepristone metabolite cross the placental barrier during the second trimester, the efficacy of placental transfer decreases with advancing pregnancy. ${ }^{4}$ Various studies conducted on induction of labor in live term pregnancies with mifepristone in doses of $200-400 \mathrm{mg}$ have shown an improvement in cervical ripeness and increased rates of spontaneous labour with no serious maternal or fetal side effects. ${ }^{5}$

The aim of this study was to compare the efficacy and outcome of oral mifepristone versus intracervical instillation of PG-E2 gel in pre-induction cervical ripening for parturition.

\section{METHODS}

This prospective study was performed on uncomplicated antenatal women who had clear indication for induction of labour, admitted in antenatal ward and labour ward of Base Hospital Delhi Cantonment which is a tertiary care obstetric referral centre. The study duration was two years between January 2018 to December 2019. The study was approved by the institute ethical committee. One hundred antenatal women were recruited for the study; 50 in mifepristone arm and 50 in PG-E2 gel arm. Any singleton term pregnancy in vertex presentation with intact membranes and bishop's score 2 of $<4$ was included in the study. Any contraindication for vaginal delivery and any contraindication for mifepristone or PGE2 were considered as exclusion criteria. A written informed consent was taken from all participants. Randomization was ensured by a computer-generated randomization sequence.

On admission, a detailed history, and complete general and obstetric examination were carried out. Vaginal examination was done under strict aseptic precautions and the Bishop's Score was recorded. Gestational age was calculated by Naegle's rule and a routine obstetric scan for fetal maturity and well-being was done. ${ }^{6}$ Once the inclusion criteria were fulfilled and cephalopelvic disproportion was ruled out, the patient was prepared and transferred to the labour ward. Indication for induction was noted after reaffirming that there was no contraindication for induction or vaginal delivery.

Participants in the mifepristone arm were given tablet mifepristone $200 \mathrm{mg}$ orally and those in PG-E2 gel group received endocervical instillation of PGE2 gel $0.5 \mathrm{mg}$ on day 1. They were observed for maternal vitals, uterine activity, bleeding or leaking per vaginum and fetal heart rate. Participants in the PG-E2 gel were reassessed at 6 hours of previous PG-E2 gel application and a second instillation of PG-E2 was done if found necessary. No second dose of mifepristone was administered to any participant in the mifepristone arm. After a wait period of 24 hours or when the Bishop score was $>6$ or when the cervical dilatation was $>2 \mathrm{~cm}$ or when the membranes ruptured or when the patient was well in labour whichever is earlier labour was accelerated with oxytocin infusion. Partographic monitoring of labour was done in all patients. Induction of labour was considered successful if the parturient delivered within 48 hours of application of mifepristone or first dose of PG-E2 gel. Delivery after 48 hours and Caesarean delivery were considered unsuccessful induction. Duration of each stage of labour, blood loss at third stage and baby particulars were recorded. Both mother and baby were observed for postnatal complications if any.

\section{Statistical analysis}

Data were analysed and all the values were expressed as mean \pm standard deviation or as percentages. Statistical comparison was done by students paired and unpaired $\mathrm{t}-$ test and chi-square test. A 'p' value less than 0.05 was considered significant.

\section{RESULTS}

Confounding factors such as age, parity and period of gestation (POG) were found to be similar in both the study groups as depicted in Table 1. Most patients were in the age group of 21 to 29 years.

Bishop's score at the time of administration of mifepristone or first dose of PG-E2 gel was also found to be comparable in both the groups as depicted in Table 2 . Most patients, $74 \%(\mathrm{n}=37)$ in mifepristone group and $62 \%(n=31)$ in PG-E2 Gel group had a bishop's score of ' 2 ' at the start of the study. The minimum bishop's score recorded was ' 0 ' and the maximum was ' 3 '.

Outcome parameters are tabulated in Table 3. There was a significant improvement in bishop's score in mifepristone group, $5.0 \pm 1.55$, as compared to PG-E2 gel group 3.64 \pm 2.14 ; p value 0.001 . Sixty six percent $(n=33)$ of women in mifepristone group required induction/augmentation with oxytocin as compared to $78 \%(n=39)$ in PG-E2 gel group. In the mifepristone group, among the 6 primigravida who were not in need of oxytocin augmentation, $4(8 \%)$ had vaginal delivery within 24 hours of oral mifepristone administration. Shortest drug administration to delivery interval was 12 hours and 5 minutes. Among the 11 multigravida who were not in need of oxytocin augmentation in the mifepristone group, $9(18 \%)$ had vaginal delivery within 24 hours of oral mifepristone, of which $4(8 \%)$ had delivery within 10 hours. Shortest drug administration to 
delivery interval was 5 hours 54 minutes. Whereas in PGE2 gel group 11 antenatal women, which includes 8 primigravida and 3 multigravida, who were not in need of oxytocin augmentation were those delivered by caesarean section. In other words, in PGE2 gel group all women who had vaginal delivery were in need of oxytocin augmentation. There was no statistically significant difference in duration of first stage of labour between the two groups, $6.88 \pm 2.12$ versus $6.86 \pm 1.41$ hours; $p$ value 0.951 . Duration of second and third stage of labour was shorter in mifepristone group with statistical significance as depicted in Table 3. Drug administration to delivery interval was found to be significantly shorter with PGE2 gel group. In the mifepristone group, $3(6 \%)$ primigravida were delivered by caesarean section of which 1 (2\%) was done for failed induction and $2(4 \%)$ were done for fetal distress whereas in multigravida $3(6 \%)$ were delivered by caesarean section for fetal distress. In the PGE2 gel group, among 9 (18\%) primigravida delivered by caesarean section, $3(6 \%)$ were done for failed induction and $6(12 \%)$ were done for fetal distress whereas in multigravida $1(2 \%)$ was done for failed induction and 2 (4\%) were done for fetal distress. NICU admission was $18 \%$ in PGE2 gel as compared to $10 \%$ in mifepristone group. Apgar score at 1 minute and 5 minutes were similar in both groups.

Table 1: Distribution of confounding variables.

\begin{tabular}{|c|c|c|c|c|c|}
\hline \multirow[b]{2}{*}{ Variable } & \multirow[b]{2}{*}{ Distribution } & \multicolumn{2}{|c|}{ Mifepristone group } & \multicolumn{2}{|c|}{ PG-E2 gel group } \\
\hline & & $\begin{array}{l}\text { Primigravida } \\
(\%)\end{array}$ & $\begin{array}{l}\text { Multigravida } \\
(\%)\end{array}$ & $\begin{array}{l}\text { Primigravida } \\
(\%)\end{array}$ & $\begin{array}{l}\text { Multigravida } \\
(\%)\end{array}$ \\
\hline \multirow{4}{*}{ Age (years) } & $\leq 20$ & $8(16)$ & $1(2)$ & $8(16)$ & $2(4)$ \\
\hline & $21-29$ & $17(34)$ & $21(42)$ & $18(36)$ & $19(38)$ \\
\hline & $\geq 30$ & $1(2)$ & $2(4)$ & $1(2)$ & $2(4)$ \\
\hline & Total & $26(52)$ & $24(48)$ & $27(54)$ & $23(46)$ \\
\hline \multirow{4}{*}{$\begin{array}{l}\text { POG (weeks + } \\
\text { days) }\end{array}$} & 37 to $37+6$ & $9(18)$ & $10(20)$ & $9(18)$ & $9(18)$ \\
\hline & 38 to $38+6$ & $11(22)$ & $9(18)$ & $10(20)$ & $9(18)$ \\
\hline & 39 to $39+6$ & $5(10)$ & $5(10)$ & $6(12)$ & $5(10)$ \\
\hline & 40 to $40+6$ & $1(2)$ & $0(0)$ & $2(4)$ & $0(0)$ \\
\hline \multirow{4}{*}{$\begin{array}{l}\text { Indication for } \\
\text { induction }\end{array}$} & Hypertensive disorders & $12(24)$ & $11(22)$ & $11(22)$ & $10(20)$ \\
\hline & Hepatic disorders & $5(10)$ & $6(12)$ & $6(12)$ & $6(12)$ \\
\hline & Gestational diabetes & $8(16)$ & $7(14)$ & $8(16)$ & $7(14)$ \\
\hline & Postdatism & $1(2)$ & $0(0)$ & $2(4)$ & $0(0)$ \\
\hline
\end{tabular}

Table 2: Bishop's score at the start of the study.

\begin{tabular}{|lllll|}
\hline Score & Mifepristone group & & PG-E2 gel group & \\
& Primi (\%) & Multi (\%) & Primi (\%) & Multi (\%) \\
\hline $\mathbf{0}$ & $1(2)$ & - & - & - \\
\hline $\mathbf{1}$ & $7(14)$ & $1(2)$ & $8(16)$ & $5(10)$ \\
\hline $\mathbf{2}$ & $16(32)$ & $21(42)$ & $18(36)$ & $13(26)$ \\
\hline $\mathbf{3}$ & $2(4)$ & $2(4)$ & $1(2)$ & $5(10)$ \\
\hline
\end{tabular}

Table 3: Outcome parameters [mean (standard deviation) unless specified otherwise].

\begin{tabular}{|llll|}
\hline Outcome parameters & Mifepristone group & PG-E2 gel group & P value \\
\hline Maternal outcome parameters & & & 0.86 \\
\hline Mean bishop's score at the start of the study & $1.88(0.55)$ & $1.86(0.60)$ & 0.001 \\
\hline Bishop score after 24 hours /at augmentation & $6.88(1.46)$ & $5.5(2.29)$ & 0.001 \\
\hline Mean improvement in bishop's score & $5.0(1.55)$ & $3.64(2.14)$ & - \\
\hline Requirement of augmentation with oxytocin & $33(66)$ & $39(78)$ & 0.951 \\
\hline Duration of first stage of labour (hours) & $6.88(2.12)$ & $6.86(1.41)$ & 0.001 \\
\hline Duration of second stage of labour (minutes) & $22.42(5.19)$ & $26.94(6.40)$ & 0.001 \\
\hline Duration of third stage of labour (minutes) & $4.06(1.20)$ & $5.44(1.30)$ & 0.001 \\
\hline Drug to delivery interval (hours) & $11.47(3.85)$ & $18.73(10.04)$ & - \\
\hline Normal delivery & $43(86)$ & $37(74)$ & - \\
\hline Instrumental delivery & $1(2)$ & $1(2)$ & - \\
\hline Caesarean delivery & $6(12)$ & $12(24)$ & - \\
\hline
\end{tabular}




\begin{tabular}{|llll|}
\hline Outcome parameters & Mifepristone group & PG-E2 gel group & P value \\
\hline Mean blood loss (ml) & $248(160.66)$ & $368(222.63)$ & 0.03 \\
\hline Maternal complications (fever, GI symptoms) & $5(10)$ & $8(16)$ & - \\
\hline Neonatal outcome parameters & & & - \\
\hline Respiratory distress & $2(4)$ & $3(6)$ & - \\
\hline Meconium aspiration syndrome & $2(4)$ & $5(10)$ & - \\
\hline Apgar score at 1 minute $<7$ & $7(14)$ & $7(14)$ & - \\
\hline NICU admission & $5(10)$ & $9(18)$ & - \\
\hline
\end{tabular}

\section{DISCUSSION}

There has been a constant endeavor from obstetricians worldwide to improve their labour induction protocols so as to get more successful inductions, thereby decreasing caesarean rate. Favorability of cervix at the time of induction plays a very important role in predicting the success of induction. Various pharmacological methods have been studied in the past to make the cervix more ripe or favorable for induction. Pharmacologic agents available for cervical ripening and labor induction include prostaglandins, misoprostol, mifepristone, and relaxin. $^{7}$

Baev et al in a randomized control trial, concluded that there is a significant improvement in bishop's score 48 hours after administration of mifepristone as compared with expectant group; $2.58 \pm 1.33$ versus $1.15 \pm 0.97$, $\mathrm{p}<0.001 .^{8}$ In the same study, the authors concluded that induction to delivery interval was significantly shorter in mifepristone group: $2.69 \pm 2.06$ versus $3.77 \pm 1.86$ days, $\mathrm{p}<0.001$. In this study, mean gain in bishop's score in mifepristone group was found to be $5.0 \pm 1.55$ corroborating with the above evidence. Athawale et al in their study concluded that there is a statistically significant improvement in bishop's score within 24 hours of oral administration of $200 \mathrm{mg}$ mifepristone. ${ }^{9}$ In a similar study by Fathima et al it was found that mean improvement in bishop's score in mifepristone group was $6.68 \pm 1.69$ as compared to control group 5.8 \pm 2.15 ; $p$ value 0.001 .10 This study results are corroborating with the above evidences. Hapangama et al in their systematic review available in Cochrane database revealed that women treated with mifepristone are less likely to need augmentation with oxytocin and less likely to have caesarean delivery. ${ }^{3}$ This study also achieved similar results. Yeliker et al in their study revealed that Eight $(16 \%)$ women in mifepristone group and two (4\%) women in control group delivered vaginally within 24 hours without any need of augmentation. ${ }^{11}$ This study also fetched similar outcomes. Neonatal outcomes were similar in both the groups of this study as clearly brought out by Yelikar et al as well as Giacalone et al. ${ }^{11,12}$

\section{CONCLUSION}

Oral administration of $200 \mathrm{mg}$ mifepristone is a safe, effective and convenient alternative to intracervical instillation of prostaglandin-E2 gel for pre-induction cervical ripening. However, authors recommend further studies on larger cohorts to formulate more evidence in the same subject.

Funding: No funding sources

Conflict of interest: None declared

Ethical approval: The study was approved by the Institutional Ethics Committee

\section{REFERENCES}

1. WHO Global Survey on Maternal and Perinatal Health. Induction of labour data. Geneva, World health Organization, 2010. Available at: http://www.who.int/reproductivehealth/topics/ best_practices/global_survey. Accessed on $20^{\text {th }}$ May 2020.

2. Bishop EH. Pelvic scoring for elective induction. Obstet Gynecol. 1964;24:266-8.

3. Hapangama D, Neilson JP. Mifepristone for induction of labour. Cochrane Database Syst Rev. 2009;(3):Art No:CD002865.

4. Frydman R, Taylor S, Ulmann A. Transplancental passage of mifepristone: Lancet. 1985;2:1252-2.

5. Clark K, Ji H, Feltovich H, Janowski J, Carroll C, Chien EK. Mifepristone-induced cervical ripening: Structural, biomechanical, and molecular events. Am J Obstet Gynecol. 2006;194:1391-8.

6. Naegele FC. Erfahrungen und Abhandlungen aus dem Gebiethe der Krankheiten des weibliches Geschlechtes. Mannheim: Loeffler. 1812:280-281.

7. Tenore JL. Methods for cervical ripening and induction of labor. Am Fam Physician. 2003;67(10):2123-8.

8. Baev OR, Rumyantseva VP, Tysyachnyu OV, Kozlova OA, Sukhikh GT. Outcomes of mifepristone usage for cervical ripening and induction of labour in full-term pregnancy. Randomized controlled trial. Eur J Obstet Gynecol Reprod Biol. 2017;217:144-9.

9. Athawale R, Acharya N, Samal S, Hariharan C. Effect of mifepristone in cervical ripening for induction of labour. Int $\mathrm{J}$ Reprod Contracept Obstet Gynecol. 2013;2(1):35-8.

10. Fathima S, Nayak SR, Rao B, Praveena G, Shameem VP. Mifepristone in induction of labour at term. Int $\mathbf{J}$ Pham Biomed Res. 2013;4(3):164-6. 
11. Yelikar K, Deshpande S, Deshpande R, Lone D. Safety and efficacy of oral mifepristone in preinduction cervical ripening and induction of labour in prolonged pregnancy. J Obstet Gynecol India. 2015;65:221-5.

12. Giacalone PL, Daurés JP, Faure JM, Boulot P, Hedon B, Laffargue F. The effects of mifepristone on uterine sensitivity to oxytocin and on fetal heart rate patterns. Eur J Obstet Gynecol Reprod Biol. 2001;97(1):30-4.

Cite this article as: Dhillon $\mathrm{P}$, Biswas M, Tripathi $\mathrm{P}$, Nair VG. Comparative study of oral mifepristone and endocervical prostaglandin-E2 gel as pre-induction cervical ripening agents in parturition. Int J Reprod Contracept Obstet Gynecol 2020;9:3825-29. 